\title{
ANALISIS FAKTOR DETERMINAN PELAKSANAAN INISIASI MENYUSU DINI OLEH BIDAN DI RUMAH SAKIT UMUM ANUTAPURA PALU
}

\author{
Ni Nyoman Novita', Gusman Arsyad ${ }^{2 \mathrm{~K}}$ \\ ${ }^{1}$ Puskesmas Meko Kabupaten Poso \\ ${ }^{2}$ Prodi DIV Jurusan Kebidanan Poltekkes Kemenkes Palu \\ email Penulis Korespondensi $\left({ }^{\mathrm{K}}\right)$ : gusman.arsyad@gmail
}

\begin{abstract}
Implementation of IMD in hospitals has decreased from the previous year and has not reached the target set by the government. Some IMD implementation processes have not been carried out according to applicable standards. So that babies do not get an IMD in accordance with existing SOPs. The purpose of this study was to determine the determinant factors associated with the implementation of the IMD by midwives in the Midwifery and Maternity Room Emergency Room (IGD) at the Anutapura General Hospital in Palu. This research method is analytical with cross sectional approach. The population of this study was that all midwives in the obstetrics emergency room and maternity room at Anutapura Palu Hospital were 37 respondents. The sample in this study is total sampling. The analysis used was univariate, and bivariate analysis using the chi square test with a confidence level of $95 \%(\alpha=0.05)$. The results of statistical tests on variable knowledge of midwives with the implementation of IMD $p$ value: 0.018 ( $p$ value $<0.05$ ). APN training with the implementation of IMD $p$ value: 0.697 ( $p$ value $>0.05$ ). length of work with the implementation of IMD $p$ value: 0.029 ( $p$ value $<0.05$ ). and peer support with the implementation of IMD p value: 0.007 ( $p$ value $<0.05$ ). Conclusions there is a relationship between knowledge, length of work, peer support with the implementation of the IMD, and training factors that have nothing to do with IMD implementation. The strongest factor in the relationship is peer support. It is recommended that the Anutarapura Palu Hospital be able to motivate midwives so that they can further enhance their role in the implementation and provide support to their colleagues so that the implementation of the IMD can be carried out in accordance with applicable standards.
\end{abstract}

Keywords: Knowledge, APN Training, Duration of work, Implementation of IMD

\section{PENDAHULUAN}

\section{Latar Belakang}

Inisiasi Menyusu Dini (IMD) merupakan rekomendasi internasional dari World Health Organization (WHO) - United Nation Childrens Fund (UNICEF) tahun 1992, yang isinya telah dikembangkan oleh Kementerian Kesehatan RI. Rekomendasi tersebut menyatakan agar semua sarana pelayanan kesehatan menerapkan 10 Langkah Menuju Keberhasilan Menyusui (LMKM) atau ten Step to Succesful Breastfeeding yang salah satu isinya menganjurkan untuk membantu para ibu dalam pelaksanaan IMD setelah melahirkan (1).

World Health Organization (WHO) dan United Nation Childrens Fund (UNICEF) pada tahun 2007 mengeluarkan protokol baru tentang "ASI segera" sebagai tindakan "life saving" atau untuk menyelamatkan kehidupan bayi baru lahir yang harus diketahui setiap tenaga kesehatan. Protokol tersebut adalah melakukan kontak kulit ibu dengan kulit bayi 
segera setelah lahir selama paling sedikit satu jam dan bantu ibu mengenali kapan bayinya siap menyusui (2).

Menyusui pada satu jam pertama menyelamatkan satu juta nyawa bayi, merupakan suatu penyelamatan berdasarkan bukti ilmiah yang mengandung pesan moral sangat besar untuk semua orang demi kelangsungan hidup dan kesehatan bayi kita ${ }^{(3)}$.

Bidan adalah seseorang yang telah menyelesaikan program pendidikan bidan yang diakui oleh Negara serta memperoleh kualifikasi dan diberi izin untuk menjalankan praktik kebidanan di negeri tersebut ia harus mampu memberi supervise, asuhan dan memberi nasihat yang dibutuhkan wanita selama hamil, persalinan, dan masa pasca persalinan, memimpin persalinan atas tanggungjawabnya sendiri serta asuhan pada bayi baru lahir dan $\operatorname{anak}^{(4)}$.

Inisiasi Menyusu Dini (IMD) merupakan salah satu dalam standar Asuhan Persalinan Normal (APN). Tidak semua bidan melakukan IMD pada setiap persalinan, padahal IMD memiliki manfaat yang begitu besar bagi ibu dan juga bagi bayi. Keberhasilan atau kegagalan dalam pelaksanaan IMD dipengaruhi oleh sikap, pengetahuan dan motivasi bidan / dokter penolong persalinan itu sendiri (3).

Berdasarkan data dari Dinas Kesehatan Provinsi Sulawesi Tengah, pelaksanaan IMD pada tahun 2016 adalah 37.320 (71,3\%) dari 52.318 kelahiran hidup, capaian IMD Provinsi Sulawesi Tengah belum mencapai target nasional yang tertuang dalam Peraturan Pemerintah nomor 33 tahun 2012 pasal 6 target capaian Asi Eksklusif yang termasuk di dalamnya IMD di Indonesia adalah $100 \%{ }^{(5)}$.

Pelaksanaan IMD di Kota Palu pada tahun 2016 adalah 5.758 (82,7\%) dari 6.961 kelahiran hidup, mengalami penurunan sebesar 451 (5,4\%) dibandingkan cakupan tahun 2015 yaitu 6.209 (88,1\%) dari 7.048 kelahiran hidup. Cakupan IMD Kota Palu belum menunjukan kinerja yang maksimal sebab belum mencapai target nasional yaitu $100 \%$ dan masih banyaknya pelaksanaan IMD yang dilakukan tidak sesuai Standar Operasional Prosedur (SOP) ${ }^{(6)}$.

Pelaksanaan IMD di Rumah Sakit Umum (RSU) Anutapura Palu pada tahun 2016 yaitu $1.166(53,8 \%)$ dari 2.166 kelahiran hidup, hal tersebut masih jauh dari target jumlah cakupan IMD yaitu 100\% dengan jumlah bidan yang bertugas di Kamar Bersalin yaitu 15 orang dan IGD Kebidanan 22 orang.

Data pembanding dari RSD Madani tahun 2016 pelaksanaan IMD yaitu sebanyak 176 $(66,9 \%)$ dari 263 kelahiran hidup.

Hasil pengamatan ketika penulis di Rumah Sakit Umum Anutapura Palu pada bulan November 2017 di ruang IGD Kebidanan dan Kamar Bersalin RSU Anutapura Palu, didapatkan di RSU Anutapura Palu bahwa beberapa proses IMD dilakukan belum sesuai Standar Operasional Prosedur (SOP) yang dikarenakan bayi dibedong, bayi dibiarkan di dada ibu setelah beberapa lama (10-15 menit) atau sampai tenaga kesehatan selesai menjahit perineum, bayi diangkat kemudian disusukan kepada ibu dengan memasukan putting susu ibu langsung ke mulut bayi.

Berdasarkan studi pendahuluan yang dilakukan oleh peneliti tanggal 27 Januari 2018 pada Bidan Kepala Ruangan Kamar Bersalin dan Kepala Ruangan IGD Kebidanan dikatakan bahwa penyebab rendahnya cakupan IMD yaitu karena kurangnya pelatihan yang di ikuti, serta ada beberapa bayi yang tidak melakukan IMD karena mengalami masalah, serta bayi yang dilahirkan secara sectio cesarea tidak dilakukan IMD, selain itu masih ada petugas kesehatan yang kurang memahami apa itu IMD.

Pelaksanaan IMD terkait dengan perilaku seseorang, menurut teori model precede perilaku seseorang dipengaruhi oleh tiga faktor, yaitu faktor predisposisi (pengetahuan, sikap, dan karakteristik masyarakat), faktor pendukung (pelatihan, sosialisasi), dan faktor 
pemungkin (sikap dan perilaku petugas kesehatan atau petugas lain, yang merupakan kelompok referensi dari perilaku masyarakat) ${ }^{(7)}$.

\section{Tujuan}

Tujuan penelitian ini adalah untuk mengetahui faktor determinan yang berhubungan dengan pelaksanaan IMD oleh bidan di IGD Kebidanan dan Kamar Bersalin RSU Anutapura Palu diantaranya yaitu Pengetahuan, pelatihan APN, Lama Kerja dan dukungan teman sejawat

\section{METODE PENELITIAN}

Jenis penelitian ini adalah analitik dengan pendekatan cross sectional. Penelitian ini dilaksanakan pada bulan Juni 2018 di IGD Kebidanan dan Kamar Bersalin RSU Anutapura Palu. Populasi pada penelitian ini adalah seluruh bidan yang terdaftar sebagai tenaga kesehatan baik PNS maupun honorer di Kamar Bersalin dan IGD Kebidanan RSU Anutapura Palu berjumlah 37 responden. Besar sampel dalam penelitian ini adalah 37 bidan. Teknik pengambilan sampel dalam penelitian ini menggunakan sampling total. analisis data dalam penelitian ini menggunakan analisis statistik Chi-Square dengan menggunakan bantuan Komputer

\section{HASIL PENELITIAN}

\section{Analisis Univariat}

Distribusi Frekuensi Pengetahuan, Pelatihan, Lama Kerja, Dukungan Tenaga Kesehatan, Pelaksanaan IMD Oleh Bidan di IGD Kebidanan dan Kamar Bersalin RSU Anutapura Palu tahun 2018, dapat dilihat pada table berikut :

Tabel 1

Distribusi frekwensi Pengetahuan, Pelatihan, Dukungan teman dan Pelaksanaan IMD oleh Bidan di RSU Anutapura Palu Tahun 2018

\begin{tabular}{lcc}
\hline \multicolumn{1}{c}{ Variabel } & Frekuensi (f) & Presentase (\%) \\
\hline Pengetahuan & & \\
$\quad$ Baik & 14 & 37,8 \\
Kurang & 23 & 62,2 \\
Pelatihan & & \\
$\quad$ Pernah & 16 & 43,2 \\
$\quad$ Tidak Pernah & 21 & 56,8 \\
Lama Kerja & 18 & 48,6 \\
$\quad$ Baru & 19 & 51,4 \\
Lama & & \\
Dukungan Teman Sejawat & 22 & 59,5 \\
$\quad$ Pernah & 15 & 40,5 \\
$\quad$ Tidak Pernah & & 43,2 \\
Pelaksanaan & 16 & 56,8 \\
$\quad$ Sesuai Standar & 21 & 100 \\
$\quad$ Tidak Sesuai Standar & 37 & \\
\hline Jumlah & & \\
\hline
\end{tabular}


Berdasarkan tabel 1 di atas dapat diketahui bahawa dari 37 yang menjadi responden pengetahuan bidan dengan kategori baik sebanyak 14 responden $(37,8 \%)$ dan kategori kurang baik 23 responden $(62,2 \%)$. Pelatihan bidan dengan kategori pernah sebanyak 16 responden $(43,2 \%)$ dan kategori tidak pernah sebanyak 21 responden $(56,8 \%)$. Lama kerja bidan dengan kategori baru sebanyak 18 responden $(48,6 \%)$ dan kategori lama sebanyak 19 responden $(51,4 \%)$. Dukungan teman sejawat dengan kategori pernah sebanyak 37 responden $(59,5 \%)$ dan kategori tidak pernah sebanyak 15 responden $(40,5 \%)$. Pelaksanaan IMD yang dilakukan bidan sesuai standar sebanyak 16 responden $(43,2 \%)$ dan tidak sesuai standar sebanyak 21 responden $(56,8 \%)$.

\section{Analisis Bivariat}

Tabel 2

Hubungan Pengetahuan Bidan Dengan Pelaksanaan IMD Di IGD Kebidanan dan Kamar Bersalin RSU Anutapura Palu Tahun 2018

\begin{tabular}{|c|c|c|c|c|c|c|c|}
\hline \multirow{3}{*}{ Pengetahuan } & \multicolumn{4}{|c|}{ Pelaksanaan } & \multirow{2}{*}{\multicolumn{2}{|c|}{ Total }} & \multirow{3}{*}{ P. value } \\
\hline & \multicolumn{2}{|c|}{ Sesuai standar } & \multicolumn{2}{|c|}{$\begin{array}{l}\text { Tidak sesuai } \\
\text { standar }\end{array}$} & & & \\
\hline & f & $\%$ & $\mathrm{~F}$ & $\%$ & $f$ & $\%$ & \\
\hline Baik & 10 & 71,4 & 4 & 28,6 & 14 & 100 & 0,018 \\
\hline Kurang & 6 & 26,1 & 17 & 73,9 & 23 & 100 & \\
\hline Total & 16 & 43,2 & 21 & 56,8 & 37 & 100 & \\
\hline
\end{tabular}

Pada tabel 2 menunjukan bahwa dari 37 responden, bidan yang berpengetahuan baik yang melaksanakan IMD tidak sesuai standar sebanyak 4 responden $(28,6 \%)$ dan responden yang berpengetahuan kurang yang melaksanakan IMD tidak sesuai standar sebanyak 17 responden (73,9\%). Berdasarkan hasil uji "chi square" didapatkan nilai $p$ : 0,018 ( $p$ value $\leq$ 0,05), maka Ha diterima dan H0 ditolak yang artinya ada hubungan pengetahuan bidan dengan pelaksanaan IMD di IGD Kebidanan dan Kamar Bersalin RSU Anutapura Palu.

Tabel 3

Hubungan Pelatihan Dengan Pelaksanaan IMD Di IGD Kebidanan dan Kamar Bersalin RSU Anutapura Palu Tahun 2018

\begin{tabular}{|c|c|c|c|c|c|c|c|}
\hline \multirow{3}{*}{ Pelatihan } & \multicolumn{4}{|c|}{ Pelaksanaan } & \multirow{2}{*}{\multicolumn{2}{|c|}{ Total }} & \multirow{3}{*}{ P. value } \\
\hline & \multicolumn{2}{|c|}{ Sesuai standar } & \multicolumn{2}{|c|}{$\begin{array}{c}\text { Tidak sesuai } \\
\text { standar }\end{array}$} & & & \\
\hline & $\bar{F}$ & $\%$ & $\mathrm{f}$ & $\%$ & $\mathrm{f}$ & $\%$ & \\
\hline Pernah & 8 & 50 & 8 & 50 & 16 & 100 & 0,697 \\
\hline Tidak pernah & 8 & 38,1 & 13 & 61,9 & 21 & 100 & \\
\hline Total & 16 & 43,2 & 21 & 56,8 & 37 & 100 & \\
\hline
\end{tabular}

Pada tabel 3 menunjukan bahwa dari 37 responden, bidan yang pernah mengikuti pelatihan yang melaksanakan IMD tidak sesuai standar yaitu 8 responden $(50 \%)$ dan responden yang tidak pernah mengikuti pelatihan yang melaksanakan IMD tidak sesuai standar sebanyak 13 responden (61,9\%). Berdasarkan hasil uji "chi square” diperoleh nilai 
$p$ : 0,697 karena ( $p$ value $>0,05$ ), maka Ha ditolak dan H0 diterima yang artinya tidak ada hubungan pelatihan bidan dengan pelaksanaan IMD di IGD Kebidanan dan Kamar Bersalin RSU Anutapura Palu.

Tabel 4

Hubungan Lama Kerja Bidan Dengan Pelaksanaan IMD Di IGD Kebidanan dan Kamar Bersalin RSU Anutapura Palu Tahun 2018

\begin{tabular}{|c|c|c|c|c|c|c|c|}
\hline \multirow{3}{*}{ Lama Kerja } & \multicolumn{4}{|c|}{ Pelaksanaan } & & & \multirow{3}{*}{ P. value } \\
\hline & \multicolumn{2}{|c|}{ Sesuai standar } & \multicolumn{2}{|c|}{$\begin{array}{c}\text { Tidak sesuai } \\
\text { standar }\end{array}$} & \multicolumn{2}{|c|}{ Total } & \\
\hline & $f$ & $\%$ & $\mathrm{f}$ & $\%$ & $\mathrm{f}$ & $\%$ & \\
\hline Lama & 12 & 63,2 & 7 & 36,8 & 19 & 100 & 0,029 \\
\hline Baru & 4 & 22,2 & 14 & 77,8 & 18 & 100 & \\
\hline Total & 16 & 43,2 & 21 & 56,8 & 37 & 100 & \\
\hline
\end{tabular}

Pada Tabel 4 menunjukan bahwa dari 37 responden, bidan yang masa kerjanya lama yang melaksanakan IMD tidak sesuai standar yaitu sebanyak 7 responden $(36,8 \%)$ dan responden dengan masa kerja baru yang melaksanakan IMD tidak sesuai standar sebanyak 14 responden (77,8\%). Berdasarkan hasil uji "chi square" diperoleh $p: 0,029$ karena ( $p$ value $\leq 0,05)$, maka Ha diterima dan H0 ditolak yang artinya ada hubungan antara lama kerja bidan dengan pelaksanaan IMD di IGD Kebidanan dan Kamar Bersalin RSU Anutapura Palu.

Tabel 5

Hubungan Dukungan Teman Sejawat Dengan Pelaksanaan IMD Di IGD Kebidanan dan Kamar Bersalin RSU Anutapura Palu Tahun 2018

\begin{tabular}{|c|c|c|c|c|c|c|c|}
\hline \multirow{3}{*}{$\begin{array}{c}\text { Dukungan } \\
\text { Teman } \\
\text { Sejawat }\end{array}$} & \multicolumn{4}{|c|}{ Pelaksanaan } & \multirow{2}{*}{\multicolumn{2}{|c|}{ Total }} & \multirow{3}{*}{ P. value } \\
\hline & \multicolumn{2}{|c|}{ Sesuai standar } & \multicolumn{2}{|c|}{ Tidak sesuai standar } & & & \\
\hline & $\mathrm{f}$ & $\%$ & $\mathrm{f}$ & $\%$ & $\mathrm{~F}$ & $\%$ & \\
\hline Pernah & 14 & 63,6 & 8 & 36,4 & 22 & 100 & \\
\hline Tidak Pernah & 2 & 13,3 & 13 & 86,7 & 15 & 100 & \\
\hline Total & 16 & 43,2 & 21 & 56,8 & 37 & 100 & \\
\hline
\end{tabular}

Pada Tabel 5 menunjukan bahwa dari 37 responden, bidan yang mendapat dukungan teman sejawat yang melaksanakan IMD tidak sesuai standar yaitu 8 responden $(36,4 \%)$ dan responden yang tidak mendapat dukungan teman sejawat yang tidak melaksankan IMD sebanyak 13 responden (86,7\%). Berdasarkan hasil uji menggunakan "chi square" diperoleh nilai $p$ : 0,007 karena ( $p$ value $\leq 0,05$ ), maka Ha diterima dan $\mathrm{H} 0$ ditolak yang artinya ada hubungan antara dukungan teman sejawat dengan pelaksanaan IMD di IGD Kebidanan dan Kamar Bersalin RSU Anutapura Palu. 


\section{PEMBAHASAN}

\section{Hubungan pengetahuan bidan dengan pelaksanaan IMD di IGD Kebidanan dan Kamar Bersalin RSU Anutapura Palu}

Hasil penelitian ini menunjukan bahwa sebagian besar bidan di RSU Anutapura Palu memiliki pengetahuan kurang di bandingkan dengan yang memiliki pengetahuan yang baik. Hasil uji statistic Chi-Square menunjukan bahwa nilai $p$.value $=0,018$ menunjukan $p, 0,05$ $(0,018<0,05)$ yang artinya bahwa ada hubungan pengetahuan bidan dengan pelaksanaan IMD oleh bidan di IGD Kebidanan dan Kamar Bersalin RSU Anutapura Palu. Faktor pengetahuan dapat mempengaruhi kinerja bidan dalam pelaksanaan IMD yang sesuai standar.

Hal ini karenan pengetahuan yang kurang dapat di pengaruhi oleh faktor usia karena usia muda memiliki kematangan berpikir yang berbeda dengan usia yang sudah tua. Menurut Budi \& Riyanto tahun $2013^{(8)}$ bahwa semakin bertambahnya usia maka akan semakin berkembang pula daya tangkap dan pola pikirnya sehingga pengetahuan yang diperoleh juga akan semakin membaik dan bertambah. Perilaku yang didasari oleh pengetahuan akan lebih efektif dari pada perilaku yang tidak di dasari oleh pengetahuan. Pengetahuan bidan mengenai IMD akan berpengaruh terhadap pelaksanaan IMD oleh Bidan sesuai standar. Hal ini membuktikan bahwa pengetahuan sangat penting dan berperan dalam membentuk perilaku seseorang termasuk dalam melaksanakan praktik IMD sesuai standar. Maka dari itu peneliti menyarankan agar pendidikan bagi bidan terus di tingkatkan kualitasnya baik formal atau nonformal khususnya dalam pelaksanaan IMD.

Hasil penelitian ini sejalan dengan penelitian yang telah dilakukan oleh Indrayani tahun $2013^{(9)}$ menunjukan bahwa pengetahuan berhubungan dengan pelaksanaan IMD dengan pengetahuan baik yang dilaksanakan sepenuhnya $36,3 \%$ dan pengetahuan kurang yang tidak dilaksanakan 16 responden $94,1 \%$. Pengetahuan bidan tentang standar pelayanan kebidanan harus ditingkatkan karena jika tidak mengerti tentang isi standar pelayanan kebidanan, bidan dalam melakukan pelayanan tidak komprehensif, mutu pelayanan tidak bagus dan manfaat dari pelaksanaan tidak tercapai dengan baik bagi bayi dan ibu. Hal ini membuktikan bahwa pengetahuan sangat penting dan berperan dalam membentuk perilaku seseorang termasuk dalam melaksanakan praktik IMD secara baik. Pengetahuan yang baik diharapkan bidan dapat lebih peduli dan mau melaksanakan IMD pada setiap pertolongan persalinan.

Hasil penelitian ini sejalan dengan penelitian Octarina tahun $2013^{(11)}$, diketahui hasil penelitian menunjukan bahwa pada variabel pengetahuan menunjukan $p$ value $=0,014$ $(<0,05)$ maka $\mathrm{H} 0$ di tolak. Hasil analisis hubungan menunjukan bahwa ada hubungan yang signifikan antara pengetahuan dengan perilaku bidan dengan pelaksanaan IMD. Sama halnya dengan penelitian ${ }^{(12)}$, berdasarkan uji statistik chi square dengan nilai $p$ value $=0,006 \quad(<$ 0,05 ) yang berarti ada hubungan bermakna antara bidan yang berpengetahuan tinggi dengan bidan yang berpengetahuan rendah terhadap kepatuhan bidan dalam melakukan IMD.

\section{Hubungan pelatihan APN dengan pelaksanaan IMD di IGD Kebidanan dan Kamar Bersalin RSU Anutapura Palu}

Hasil analisis univariat menunjukan bahwa sebagian besar bidan yang tidak pernah mengikuti pelatihan dibandingkan bidan yang pernah mengikuti pelatihan. Hasil uji ChiSquare menunjukan bahwa nilai $p=0,697$ menunjukan nilai $p>0,05(0,697>0,05)$ bahwa tidak ada hubungan pelatihan APN dengan pelaksanaan IMD di IGD Kebidanan dan Kamar Bersalin RSU Anutapura Palu. Faktor pelatihan tidak memberikan pengaruh yang besar dalam pelaksanaan IMD yang sesuai standar.

Menurut asumsi pelatihan sangat di perlukan dalam melakukan pelaksanaan IMD, dengan adanya suatu pelatihan dapat meningkatkan pengetahuan dan keterampilan yang

39 | Penerbit: Jurusan Kebidanan, Poltekkes Kemenkes Palu 
dimiliki oleh bidan. ${ }^{(13)}$ tujuan dari pelatihan yaitu adanya peningkatan perolehan kemampuan seseorang dalam melaksanakan tugas pekerjaan yang menjadi tanggungjawabnya. Responden yang pernah mengikuti pelatihan seharusnya dapat mengaplikasikan ilmu yang didapatkan dari pelatihan, namun masing-masing individu berbeda, ada yang mudah untuk mengubah perilakunya untuk bertindak, ada yang memerlukan tahap yang lama untuk berubah, dan ada yang telah mengikuti pelatihan namun karena kebiasaan bekerja yang lebih praktis, mudah dan cepat selesai serta tidak merepotkan sehingga perilaku pelaksanaan IMD tidak dilaksanakan.

Hasil penelitian ini sejalan dengan penelitian yang telah dilakukan Yunista 2010 (15) bahwa hasil analisis menunjukan bahwa nilai $p$-value $=0,055(\geq 0,05)$, maka $\mathrm{H} 0$ gagal di tolak, yang berarti bahwa tidak ada hubungan antara pelatihan dengan pelaksanaan IMD oleh bidan.

Penelitian ini sejalan dengan Indrayani tahun $2013^{(9)}$, dengan hasil penelitian menunjukan bahwa pada variabel pelatihan menunjukan nilai $p$ value $=0,054(\geq 0,05)$, maka H0 di terima. Hasil analisis menunjukan bahwa pelatihan tidak berhubungan dengan praktik pelaksanaan IMD.

\section{Hubungan lama kerja bidan dengan pelaksanaan IMD di IGD Kebidanan dan Kamar Bersalin RSU Anutapura Palu}

Hasil analisis uji Chi-Square menunjukan bahwa nilai $p=0,029$ menunjukan nilai $p<$ $0,05(0,029<0,05)$ yang berarti bahwa ada hubungan lama bekerja bidan dengan pelaksanaan IMD di IGD Kebidanan dan Kamar bersalin RSU Anutapura Palu. Faktor lama kerja dapat mempengaruhi kinerja bidan dalam pelaksanaan IMD yang sesuai standar.

Menurut asumsi peneliti, bidan yang sudah lama bekerja mempunyai pengalaman yang lebih banyak terkait pelaksanaan IMD yang mengakibatkan jumlah bidan yang sudah lama bekerja akan cenderung lebih banyak melakukan pelaksanaan sesuai standar dibandingkan tidak sesuai standar. ${ }^{(14)}$ lama kerja seseorang dapat meningkatkan pengetahuan, serta keterampilan dari seseorang. Namun, kualitas yang dihasilkan tetap bergantung kepada individu yang bersangkutan. Untuk itu, peneliti menyarankan bidan yang dengan kategori baru bekerja sebaiknya mendapat bimbingan maupun asistensi terhadap bidan dengan kategori lama bekerja agar bidan yang baru bekerja tersebut dengan cepat mendapatkan pengalaman yang lebih banyak dan mendapat keterampilan yang lebih banyak lagi.

Hasil penelitian ini sejalan dengan yang dikemukakan Yunista tahun $2012^{(15)}$ bahwa semakin tinggi lama kerja bidan maka kecenderungan untuk melaksanakan IMD semakin tinggi, berdasarkan hasil analisis menggunakan chi square di dapatkan nilai $p$-value $=0,011$ $(<0,05)$,yang artinya ada hubungan antara lama kerja bidan dengan pelaksanaan IMD.

Hasil penelitian Indrayani tahun $2013^{(9)}$, uji hipotesis menggunakan chi square menujukan bahwa pada variabel lama kerja menunjukan $p$-value $=0,017(<0,05)$ maka H0 di tolak, yang artinya ada hubungan antara lama kerja bidan dengan praktik pelaksanaan IMD. Dimana makin lama pengalaman kerja maka makin terampil seseorang dalam melakukan pekerjaan yang ditekuninya.

Penelitian Selvi, dkk. $2015^{(10)}$, menunjukan bahwa berdasarkan hasil analisis uji statistik sebagian besar bidan yang lama kerjanya kategori lama dalam melaksanakan IMD sesuai standar sebanyak $27(32,5 \%)$ dan bidan yang lama kerjanya baru sebanyak $15(18,1 \%)$, nilai $p$-value $=0,037<0,05$ artinya terdapat hubungan yang bermakna antara lama kerja dengan Pelaksanaan (IMD).

\section{Hubungan dukungan teman sejawat dengan pelaksanaan IMD di IGD Kebidanan dan Kamar Bersalin RSU Anutapura Palu}

Hasil analisis uji Chi-Square menunjukan bahwa nilai $p=0,007$ menunjukan nilai $p<$ $0,05(0,007<0,05)$ yang berarti bahwa ada hubungan dukungan teman sejawat dengan 
pelaksanaan IMD di IGD Kebidanan dan Kamar bersalin RSU Anutapura Palu. Faktor dukungan teman sejawat mempengaruhi kinerja bidan dalam pelaksanaan IMD yang sesuai standar.

Menurut asumsi peneliti dukungan dari teman sejawat sangat berperan penting dalam terlaksananya inisiasi menyusui dini, kurangnya dukungan teman sejawat disebabkan oleh kurangnya pengetahuan bidan mengenai IMD serta kurangnya bidan dalam bersosialisasi. Untuk itu, peneliti menyarankan agar petugas kesehatan dapat mengaplikasikan semua ilmu yang telah di peroleh selama menempuh pendidikan, serta lebih memberikan dukungan bagi para teman sejawat agar proses pelaksanaan IMD dapat sesuai dengan prosedur yang ada.

Hasil penelitian ini sejalan dengan penelitian yang di kemukakan Khoniasari tahun $2015^{(16)}$ bahwa peran tenaga kesehatan khususnya bidan memiliki hubungan positif dan secara statistic hubungan peran bidan dengan pelaksanaan IMD terbukti signifikan. Berdasarkan data hasil penelitian tersebut, peran bidan yang besar memiliki kemungkinan meningkatkan pelaksanaan IMD oleh ibu 34,27 kali lebih besar dari peran bidan yang kecil.

Demikian pula dengan penelitian yang dilakukan Aprina tahun $2015^{(17)}$ mengenai faktor-faktor yang berhubungan dengan pelaksanaan inisiasi menyusu dini di RSIA Mutiara Putri Bandar Lampung Tahun 2015, hasil analisis menunjukan bahwa nilai p-value 0,040 $(<0,05)$, yang artinya adanya hubungan yang signifikan antara dukungan teman sejawat dengan pelaksanaan IMD.

Hasil penelitian Rusada, dkk. tahun $2016^{(18)}$ menunjukkan bahwa nilai p-value $=0,000(<0,05)$, yang artinya adanya hubungan antara dukungan teman sejawat dengan pelaksanaan IMD. Begitu pula hasil penelitian Rompis, dkk. tahun $2017^{(19)}$, berdasarkan hasil analisis uji chi-square didapatkan hasil dengan nilai $p$-value $=0,001(<0,05)$ yang menunjukkan terdapat dukungan teman sejawat dengan pelaksanaan IMD Di Rumah Sakit Siloam Manado. Tenaga kesehatan juga memerlukan sikap yang mendukung terhadap menyusu melalui pengalaman dan pengertian mengenai berbagai keuntungan emberian ASI. Tenaga kesehatan membina atau membangun kembali kebudayaan menyusu dengan meningkatkan sikap positif yang sekaligus dapat menjadi teladan bagi wanita lainnya.

\section{Peluang pengetahuan, lama kerja, dan dukungan teman sejawat dengan pelaksanaan Inisiasi Menyusu Dini (IMD) oleh bidan di IGD Kebidanan dan Kamar Bersalin RSU Anutapura Palu}

Berdasarkan analisis bivariat dari tiga variabel yaitu pengetahuan, lama kerja dan dukungan teman sejawat. Signifikan peluang terhadap pelaksanaan Inisiasi Menyusu Dini (IMD) yaitu variabel dukungan teman sejawat dengan nilai $\mathrm{p}(0,07)$ dan nilai $\mathrm{RR}=11.375$ yang artinya dukungan teman sejawat berpeluang 11.375 kali memberikan pengaruh dalam pelaksanaan IMD yang sesuai standar.

Menurut analisa peneliti dukungan teman sejawat merupakan variabel yang paling berpeluang dalam memberikan pengaruh terhadap keberhasilan pelaksanaan IMD oleh bidan. Kurangnya dukungan dari teman sejawat menyebabkan tidak terlaksananya inisiasi menyusu dini yang sesuai standar sedangkan adanya dukungan dari teman sejawat baik dukungan emosi maupun pengetahuan memberikan manfaat yang lebih besar bagi bidan yang akan menolong persalinan dalam menerapkan IMD sesuai dengan standar. Variabel lama kerja bidan dan pengetahuan bidan kekuatan hubungannya lebih kecil karena pelaksanaan IMD dipengaruhi oleh beberapa faktor lainya juga.

Penelitian ini sejalan dengan Dinengsih tahun $2014^{(12)}$ bahwa dukungan teman sejawat berhubungan dengan kepatuhan bidan dalam melaksanakan inisiasi menyusu dini di bidan praktik mandiri di kecamatan Bekasi Timur dengan p:0,031. Hal ini sejalan dengan penelitian Khoniasari tahun $2015^{(16)}$ bahwa peran tenaga kesehatan khususnya bidan memiliki hubungan positif dan secara statistic hubungan peran bidan dengan pelaksanaan 
IMD terbukti signifikan. Berdasarkan data hasil penelitian tersebut, peran bidan yang besar memiliki kemungkinan meningkatkan pelaksanaan IMD oleh ibu 34,27 kali lebih besar dari peran bidan yang kecil.

Demikian pula dengan penelitian Sirajuddin, dkk. $2013^{(20)}$ bahwa tindakan bidan berhubungan dengan pelaksanaan IMD oleh ibu bersalin. Hasil analisis multivariate menunjukan $\mathrm{OR}=2,57$, berarti tindakan bidan berpengaruh 2,6 kali lebih besar terhadap pelaksanaan IMD dibandingkan dengan bidan yang tidak melakukan IMD.

Penelitian ini menunjukkan bahwa sebagian besar ibu yang melahirkan di fasilitas kesehatan tidak memulai menyusui dalam satu jam pertama; meskipun pemberian fasilitas kesehatan dikaitkan dengan tingkat inisiasi dini yang lebih tinggi. Temuan ini menunjukkan bahwa ibu membutuhkan dukungan lebih lanjut, dan dorongan untuk memulai menyusui.

\section{SIMPULAN DAN SARAN}

Kesimpulan penelitian ini adalah ada hubungan pengetahuan, lama kerja dan dukungan teman sejawat bidan dengan pelaksanaan inisiasi menyusu dini di IGD kebidanan dan Kamar bersalin RSU Anutapura Palu. Sementara Pelatihan APN tidak berhubungan dengan IMD. Dari variabel yang ada dukungan teman sejawat merupakan faktor yang paling dominan dalam implementasi IMD di RSU Anutapura Palu. Disarankan kepada RSU Anutapura Palu agar selalu mensukseskan program Inisiasi Menyusu Dini (IMD) melalui motivasi secara terus menerus pada bidan, agar lebih intensif lagi melakukan dukungan pada ibu bersalin agar pada pelaksanaan IMD dapat dilakukuan sesuai standar yang berlaku di Rumah Sakit. Dan kepada peneliti berikutnya perlu dilakukan penelitian lebih lanjut tentang faktor-faktor lain yang mempengaruhi pelaksanaan IMD seperti sikap, kebijakan atasan, tempat persalinan, dukungan keluarga.

\section{DAFTAR PUSTAKA}

1. Cadwell, K. \& Maffei. 2013. Buku Saku Manajemen Laktasi. Jakarta: EGC.

2. Kemenkes RI. 2013. Profil Kesehatan Indonesia Tahun 2013. Jakarta.

3. Roesli, U. 2013. Mengenal Asi Ekslusif, PT Pustaka Pembangunan. Jakarta. Swadaya Nusantara.

4. Marmi. 2014. Etika Profesi Bidan. Pustaka Pelajar : Yogyakarta.

5. Dinas Kesehatan Provinsi Sulawesi Tengah. 2016. Profil Dinas Kesehatan Provinsi Sulawesi Tengah Tahun 2016. Palu.

6. Dinas Kesehatan Kota Palu. 2016. Profil Dinas Kesehatan Kota Palu Tahun 2016. Palu.

7. Notoatmojo. 2014. Ilmu Perilaku Kesehatan.Rineka Cipta : Jakarta

8. Budi \& Riyanto. 2013. Kapita Selekta Kusioner Pengetahuan dan Sikap Dalam Penelitian Kesehatan. Salemba Medika : Jakarta.

9. Indrayani, E. 2013. Faktor - Faktor Yang Berhubungan Dengan Praktik Pelaksanaan Inisiasi Menyusu Dini Oleh Bidan Di Kota Palangka Raya Provinsi Kalimantan Tengah Tahun 2013. MUI, (Online), Jilid 5, No. 3 (http://www.lib.ui.ac.id).

10. Selvi Mohammad, A.J.M. Rantu, J.M.L. Umboh, Faktor-Faktor yang Berhubungnan dengan Pelaksanaan Inisiasi Menyusu Dini oleh Bidan di Rumah Sakit Prof. Dr. Aloei Saboe kota Gorotalo, 2015, Artikel Ilmiah JIKMU, vol.5 No.2a, April 2015

11. Octarina, A. 2013. Pengaruh etos kerja dan Disiplin Kerja Terhadap Kinerja Pegawai Pada Dinas Kebudayaan Parawisata Pemuda dan Olahraga Kabipaten Sarolangen. Kumpulan jurnal Mahasiswa Fakultas Ekonomi Unversitas Andalas, Manajemen S-1, Vol.1 (2013). 
12. Dinengsih, S. 2014. Analisis Kepatuhan Bidan Dalam Melakukan IMD Pada Proses Persalinan Di Bidan Praktik Mandiri Di Kecamatan Bekasi Timur Tahun 2014. Jurnal Skala Kesehatan, (Online), Jilid 5, No. 2, (http://ejurnalskalakesehatanpoltekkesbjm.com).

13. Kuswana, WS. 2013. Dasar-Dasar Pendidikan Vokasi dan Kejujuran. Alfabeta : Bandung.

14. Notoatmodjo, S. 2010. Promosi Kesehatan.Rineka Cipta : Jakarta

15. Yunista , V, 2012. Faktor yang mempenarhi Pelaksanaan Inisiasi Menyusu Dini (IMD) oleh Bidan di 12 Pukesmas Agam Timur Wilayah Kerja Dinas Kesehatan Agam Provinsi Sumatera Barat (Tesis) tidak dipublikasikan, Depok FKM- UI.

16. Khoniasari, A. 2015.Pengaruh Paritas, Pengetahuan Ibu, Dukungan Keluarga, dan Peran Tenaga Kesehatan Terhadap Pelaksanaan Inisiasi Menyusu Dini Di RSUD Salatiga. Tesis tidak diterbitkan. Surakarta: Pascasarjana Universitas Sebelas Maret Surakarta. (http://eprints.uns.ac.id).

17. Aprina. 2015. Faktor-Faktor Yang Berhubungan Dengan Pelaksanaan Inisiasi Menyusu Dini (IMD) Di RSIA Mutiara Putri Bandar Lampung Tahun 2015. Jurnal Skala Kesehatan, (Online), Jilid 6, No. 2, (http://ejurnalskalakesehatan-poltekkesbjm.com).

18. Rusada AD. Yusran S. Jufri NN. 2016. Faktor yang berhubungan dengan Pelaksanaan Program Inisiasi Menyusu Dini (IMD) di Puskesmas Poasia kota Kendari, Jurnal Ilmiah Mahasiswa Kesehatan Masyarakat Vol. 1 Nomor 3..

19. Rompis. Octavia. Tumurang. Marjen. Raule. Jean. 2017. Faktor-Faktor yang Berhubungan dengan Inisiasi Menyusu Dini di Rumah Sakit Siloam Manado. Program Pasca Sarjana Universitas Sam Ratulangi Manado.

20. Sirajuddin, S. Tahir A. Lumula N, Sutriani. 2013. Determinan Pelaksanaan Inisiasi Menyusui Dini. Kesmas : National Public Health Journal 8. 